\title{
Computational-mathematical modeling of decision-making using Iowa Gambling Task based on Cognitive Inputs
}

\author{
Azadeh Nesari ${ }^{1}$, Hoda Mansourian ${ }^{1}$, Alireza Moradi $^{2 *}$ iD, Babak Mohamadi ${ }^{3}$, Mir Mohsen Pedram$^{4}$ \\ 1. PhD Student of Cognitive Modeling, Institute for Cognitive Science Studies (ICSS), Tehran, Iran \\ 2. Professor of Clinical Psycology, Kharazmi University \& Head of Institute for Cognitive Science Studies, Tehran, Iran \\ 3. Faculty Member of Aja University, Head of Aja University of Medical Sciences, Tehran, Iran \\ 4. Faculty Member of Kharazmi University, Department of Cognitive Modeling of Institute for Cognitive Science Studies, Tehran, Iran
}

Recieved: 7 Jan. 2019

Revised: 13 Jun. 2019

Accepted: 16 Jun. 2019

\section{Keywords}

Computational modeling

Dynamic decision-making

Connectionist networks

Iowa Gambling Task

Corresponding author

Alireza Moradi, Institute for Cognitive Sciences Studies, Chamran Blvd, Pazhouheshkadeh Blvd, Safir Omid Blvd, Edalat Sq, 4th Phase, Pardis, Tehran, Iran

Email: Moradi@iricss.org

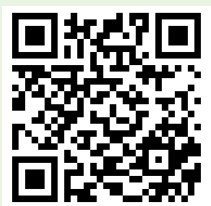

\section{Abstract}

Introduction: Investigating how individuals' decision-making is influenced by other cognitive elements and using computational modeling of decision can help us to better appreciate this cognitive function, as well as better decision-making quality. Thepresent study aimed to present a new cognitive model in the field of decision-making and to examine the model's efficacy in predicting the decisions of those participating in the Iowa decision test compared to other classical decision-making models.

Methods: In this study, 56 subjects, including 20 men and 36 womenwith an average age of 43.52, were asked to participate in the Iowa gambling task. The results of the model used were then compared with the results of the three well-known decision- making models, including expected value, expected utility, and prospect model.. The flexibility of this model by calculating the impact factor of each concept for each individual, allows us to model each person's decision-making individually and identify the concepts, which are most effective in each individual's decision-making.

Results: The obtained results revealed that the expected value, expected utility, prospect, and the proposed cognitive connectionist models predicted $36.04 \%, 42.46 \%, 49.18 \%$, and $73.02 \%$ of subjects' decisions, respectively.

Conclusion: As a result, it can be argued that the proposed cognitive connectionist model has more potential for modeling examinee's behavior in the Iowa test. It also provided a reasonable way to study the essential cognitive elements that can affect the participant's decisions. 


\title{
مدل سازى رياضياتى_محاسباتى تصميم تيرى با استفاده از آزمون آيوا بر اساس

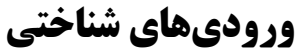

\author{
آزاده نثارى'، هدى منصوريان'، عليرضا مرادى ‘"(D)، بابك محمدى"، مير محسن يدرام
}

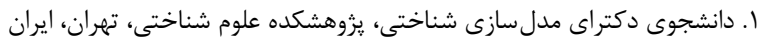

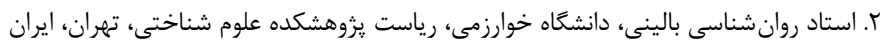

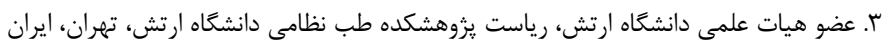

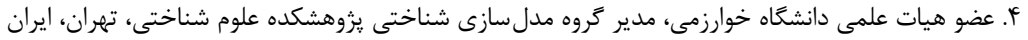

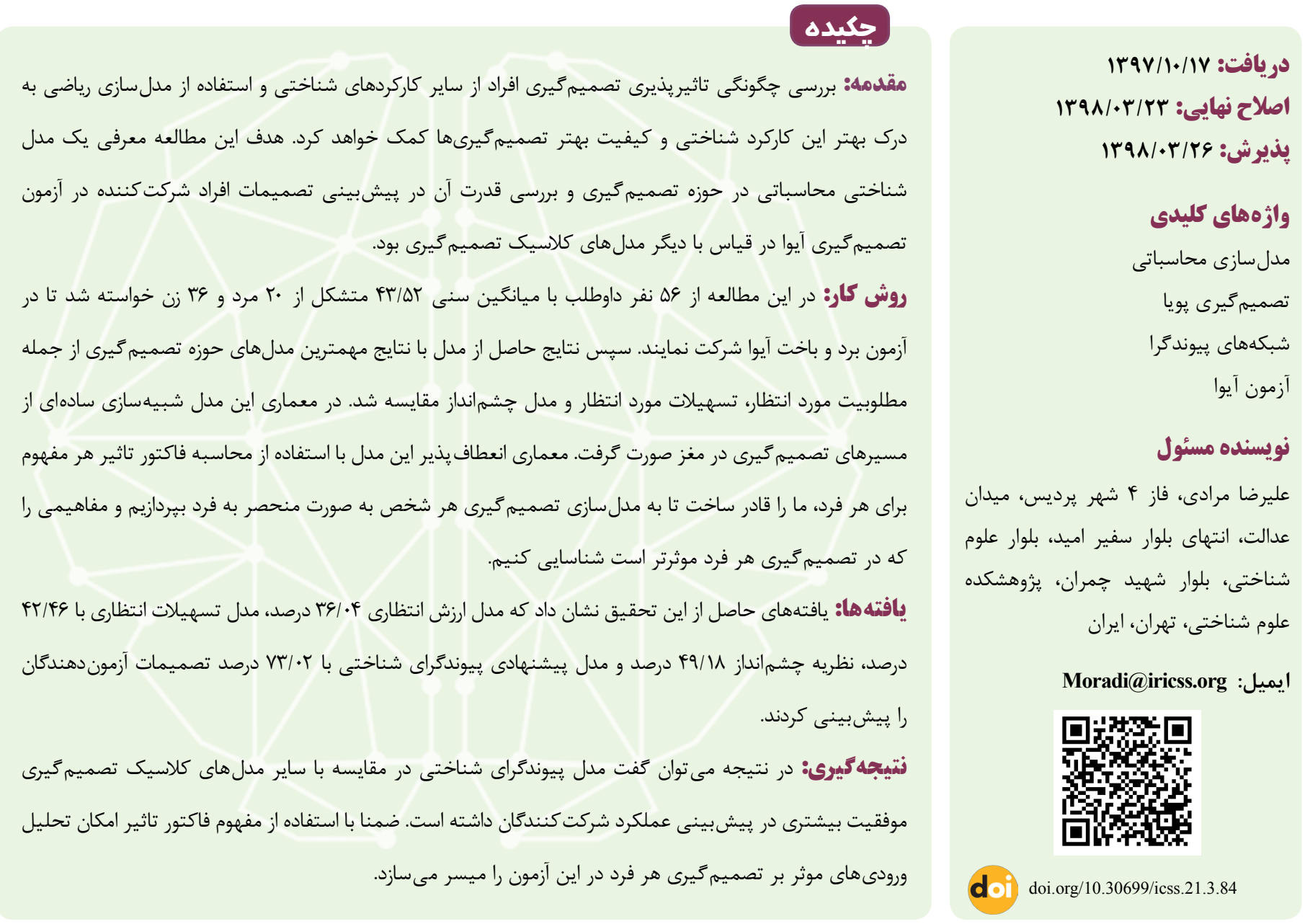

مقدمه

نتيجه را با مهمترين مدل هاى نظرى حوزه تصميمثيرى مقايسه خواهيم كرد. در حقيقت تمام فعاليتها و اقداماتى كه توسط افراد در زمينههاى مختلف انجام مىشود، به نوعى حاصل فر آيند تصميم گيرى است ( (). در واقع تصميمَيرى اساس برنامهريزى، اداره امور و مديريت در جنبه هاى فردى و اجتماعى زندكى محسوب مى شود (Y). تصميم گيرى فر آيندى
تصميم گيرى به عنوان يكى از مهمترين كاركردهاى شناختى در مطالعات بسيارى مورد توجه قرار كرفته است. يكى از مهمترين آزمونهاى مورد

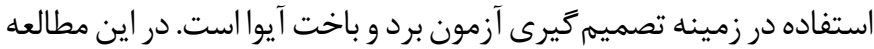
مدل پييوندگراى شناختى جديدى را معرفى خواهيم كرد و با استفاده از آن به مدلسازى تصميم گيرى افراد در اين آزمون خواهيم يرداخت و 
براى توضيح جحونكى تصميم گيرى افراد هنكام مواجه با ريسك توسعه داده شده است. نظريه مطلوبيت انتظارى به سادهترين بيان، ادعا مى كند كه تحت مفروضات خاصى، زمانى كه يك فرد بايستى بين جند ززينه مختلف انتخاب كند، كزينهاى را انتخاب مى كند كه به وى

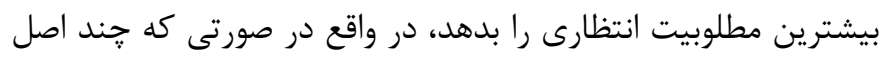

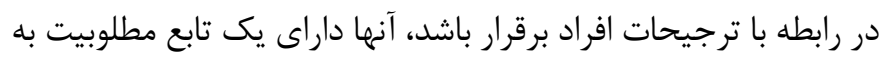
شكل تابع مطلوبيت Neumann-Morgenstern بر روى مجموعهاى از انتخابهاى مختلف هستند (به عبارت ديخر طورى رفتار مىكنند كه كويا داراى اين تابع مطلوبيت مىباشند) و زمانى كه با انتخابهاى ريسكدار مواجه مىشوند، كزينهاى را انتخاب مى كنند كه بيشترين

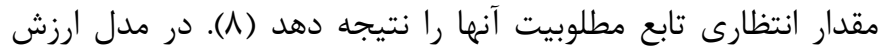
انتظارى به هر كزينه موجود براى انتخاب ارزشى نسبت داده مىشود

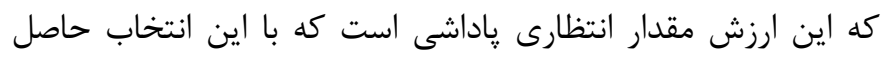

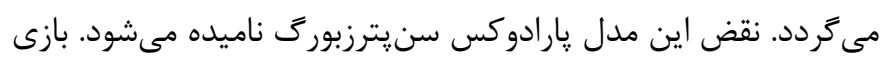

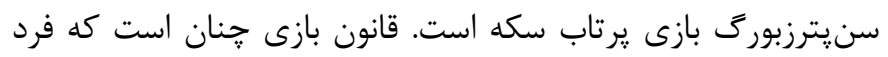

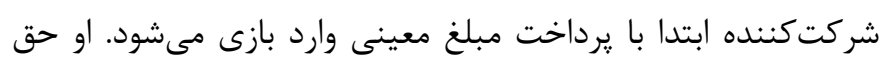
دارد تا جايى كه شير مى آيد به بازى ادامه دهد و به ازاى n بار شير باري

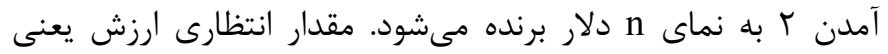
مجموع حاصلضرب احتمال هر مرتبه شير آمدن در مقدار برد، بىنهايت مىشود. اين در حالى است كه تجربه نشان داده افراد حاضر نيستند مبلغى بيش از حدود · r دلار براى شركت در بازى يرداخت كنند (9).

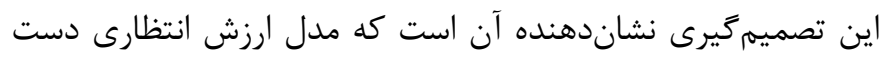

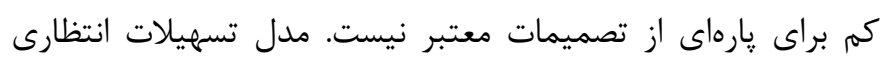

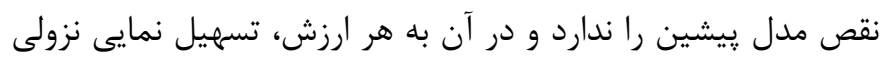

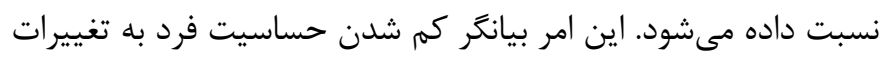
ارزش در مقادير بالا است. نظريه جشمانداز شامل سه كزاره بزرى

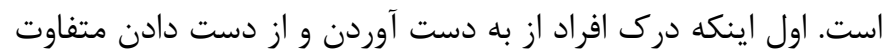

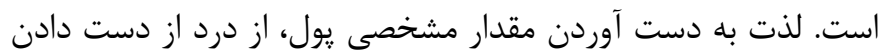
همان ميزان به مراتب كمتر است. دوم اينكه درك سود و ضرر به دانه اين موضوع بستَى دارد كه جِكونه نتايج بر اساس يك نقطه مرجع

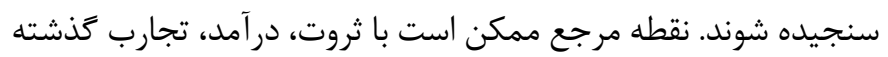

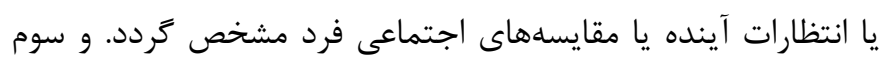

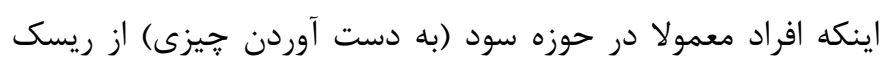
دورى مى كنند اما در حوزه ضرر (از دست دادن جيزى) به سراغ ريسك إنى إنى مىروند (V). نظر يه جشمانداز در زمينه هاى متفاوت تصميم گيرى مانند

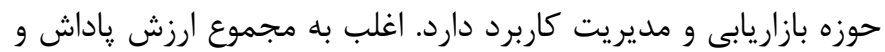
ضررهاى احتمالاتى جشم|نداز كَفته مىشود (I).
است كه با حل يك مسئله در ارتباط است و از اين رو اغلب به آن، حل مسئله نيز تفته مى شود (1). در تعريفى كلى و روان شناختى، مى توان كَفت تصميم گيرى فرآيند حل مسئلهاى است كه با به دست آمدن يك راه حل ارضاكننده به קايان مىرسد (سا).

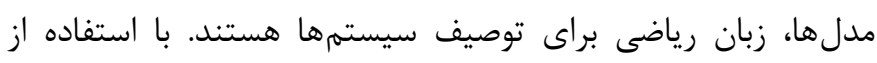

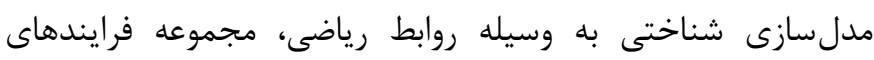

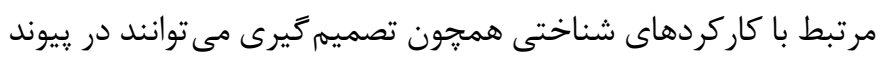
با روانشناسى و علوم اعصاب توصيف شوند. در اينجا از مدلسازى مىتوان به عنوان ابزارى براى درك بهتر كاركردهاى شناختى انسان از منظر عصبشناختى و روانشناسى استفاده كرد. در خصوص ادبيات مدل هاى تصميم گيرى مى توان كفت مدلهاى نظرى تصميم گيرى در

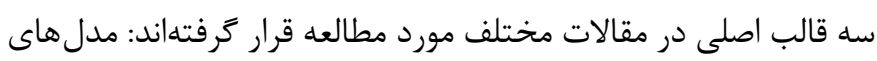

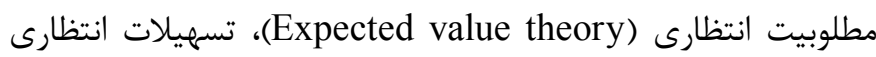
و جشمانداز (Expected utility theory) كه در اين مقاله نيز به تشريح بيشتر اين مدلها خواهيم يرداخت.

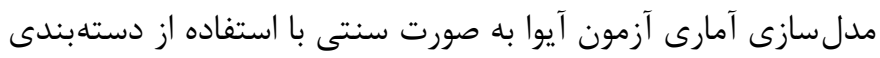

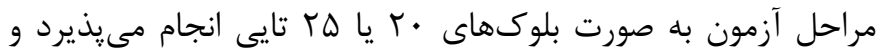
عملكرد شركت كنندكان در هر بلوك به صورت آمارى مورد بررسى قرار

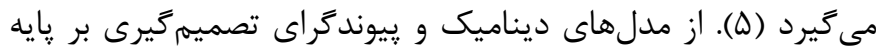

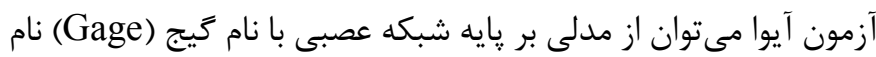

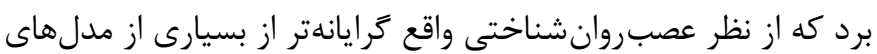

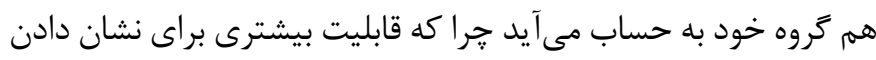

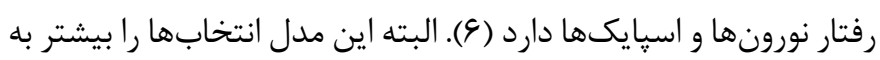
دو دسته خوب يا بد تقسيم مى كند و مناطق مختلف مغز براى دريافت

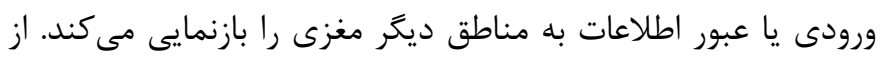

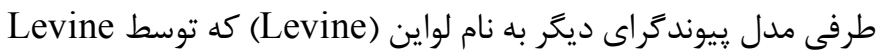
در ه •r معرفى شد كه با معادلات غير خطى ديفرانسيلى بر پايه شمارش شناختى سود و ضرر براى هر دسته كارت تعريف مىشود (V).

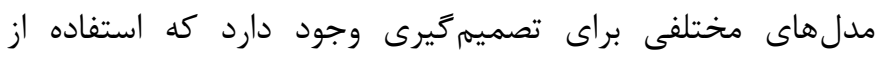

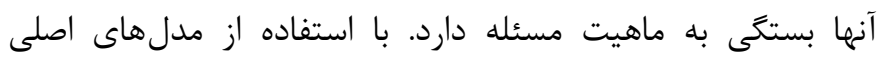

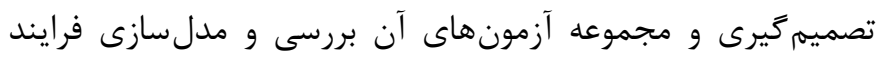

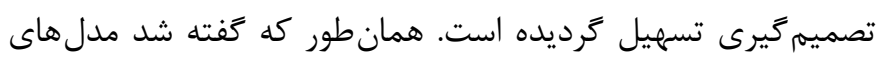
كلاسيك تصميم خيرى در سه دسته كلى مطرح مى شوند كه به طور خلاصه تشريح مىشوند: () ارزش يا مطلوبيت انتظارى: در نظريه تصميم گيرى، ارزش انتظارى يك تصميم براى يك فرد است كه با جمع كردن مطلوبيت حاصل از رخ دادن هركدام از نتايج تصميم ضرب در در احتمال رخ دادن آن تصميم، به دست مى آيد. مفهوم مطلوبيت انتظارى 
شفاهى داده شد. به صورت خلاصه دستورالعمل خَحَونكى آزمون براى

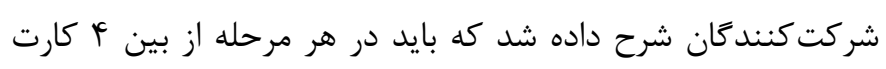

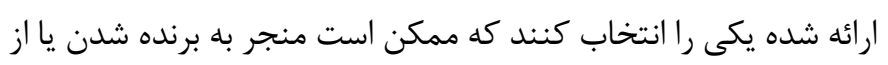

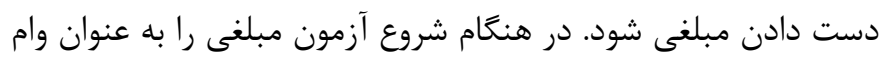

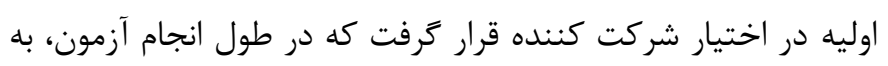

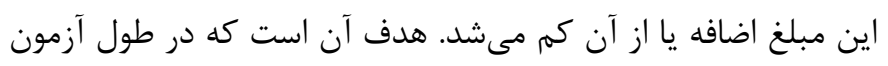

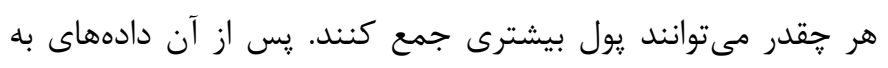

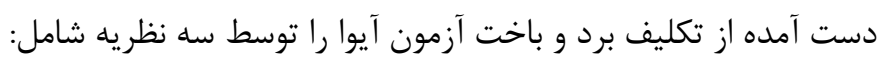
نظريه ارزش مورد انتظار، نظريه مطلوبيت مورد انتظار، نظريه جشهمانداز إنداز

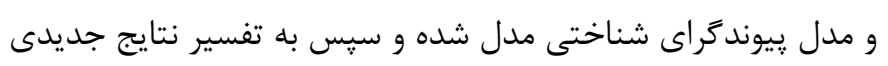
كه مىتوان از شبكه تصميم استخراج نمود يرداخته شد.

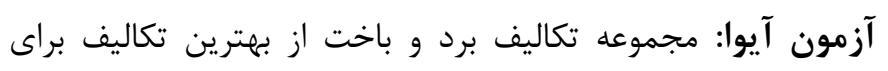
بررسى تصميمغيرى است. در ميان اين تكاليف، تكليف برد و باخت آيوا

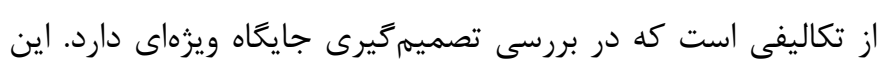

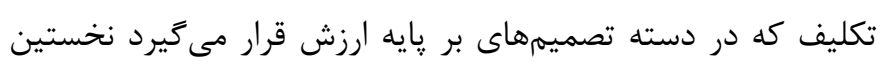

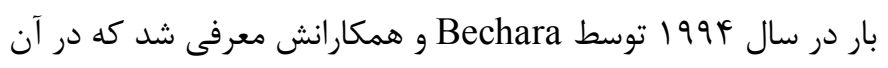
تصميم گيرى مالى فرد بر اساس انتخابهاى سودآور يا زيان آور او مورد

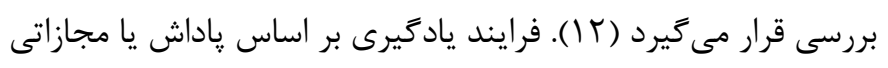

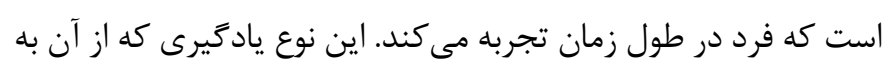

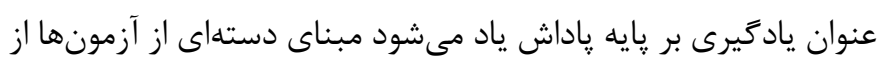

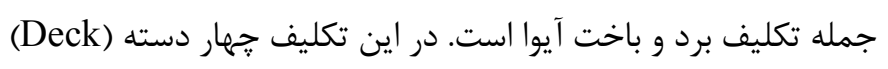

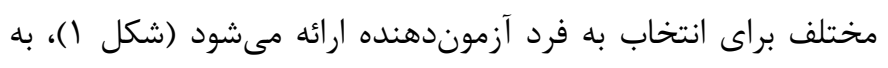
طور مرسوم دسته A شامل بردهاى به نسبت بزرى (به نسبت دسته

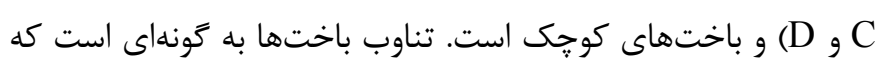

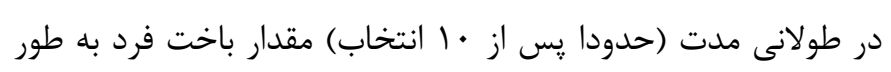

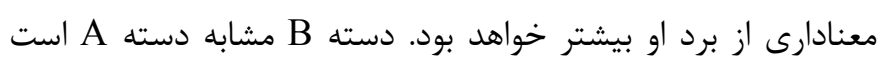

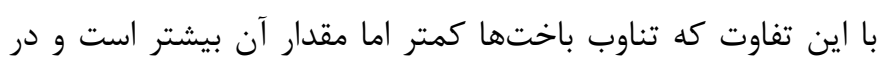

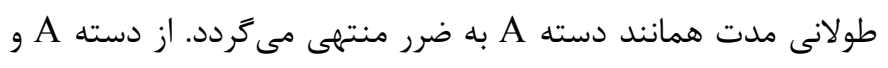

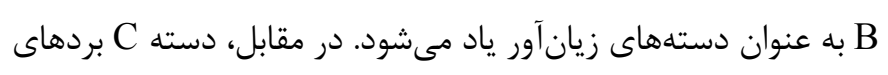

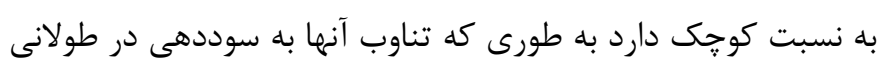

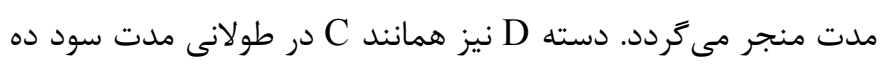

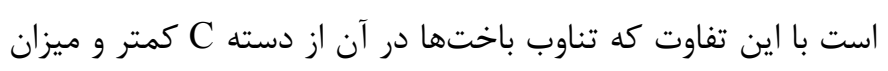

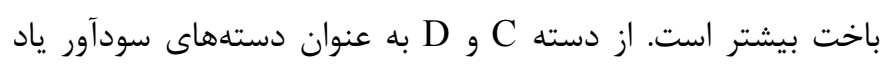

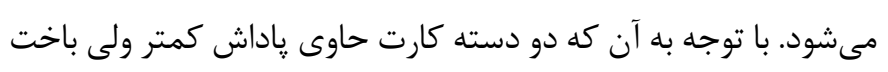

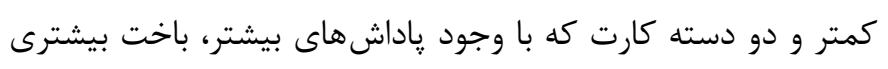

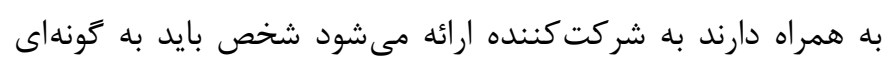

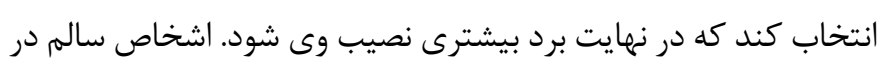

مدل محاسباتى مطرح در اين يزوهش مدلى مبتنى بردانش محاسباتى

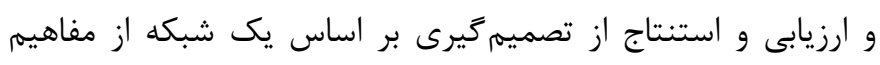

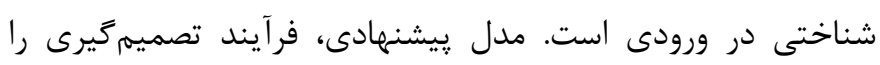

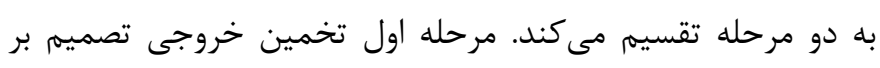

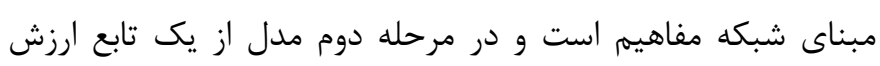

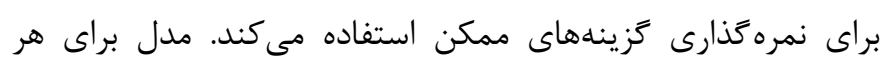

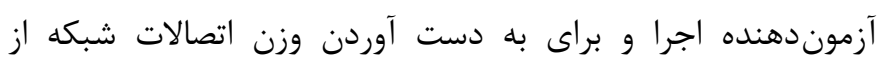

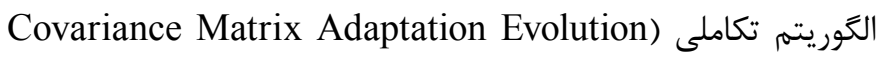
فاستفاده شد. مدل شبكه مد نظر در راستاى پيادهسازى (Strategy

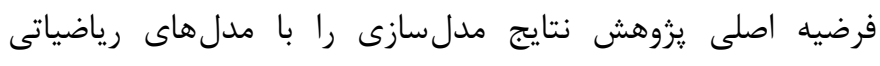

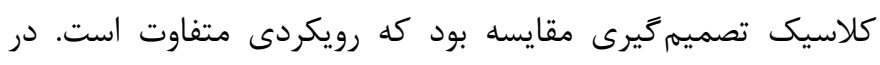

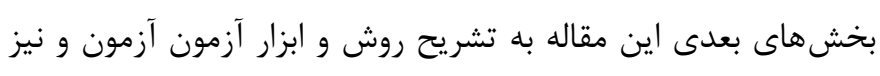

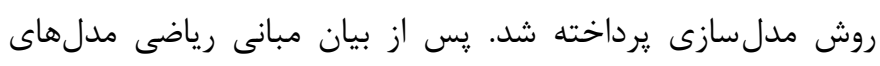

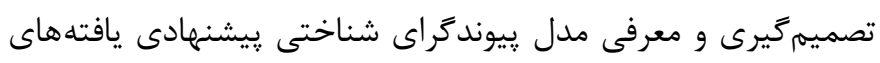
تحقيق تشريح و نتايج اين مدلها را مقايسه شد. در نهايت اين نتايج تحليل و تفسير شدند.

\section{روش كار}

جامعه آمارى اين يزوهش افراد بالاتر از • ب سال كه در اداره استاندارد

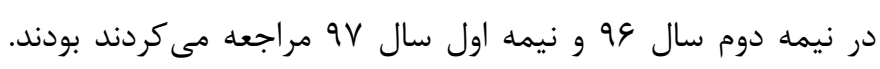

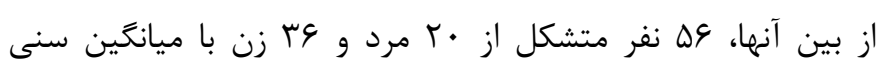

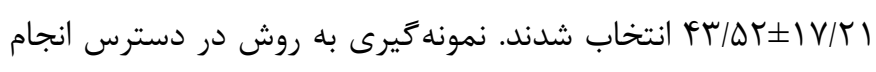

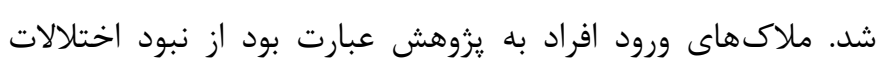

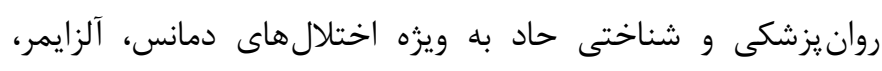

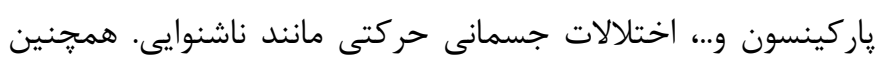

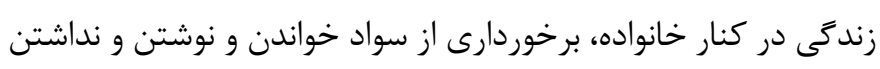

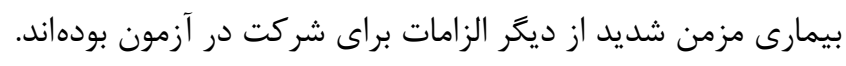

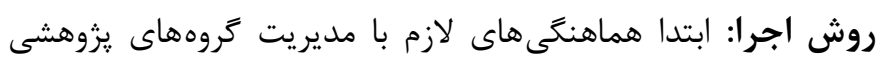

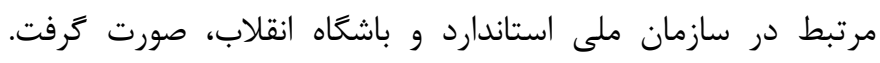
شركت كنند كان با رضايت در يزوهش شركت كردند و واز از آنها خواسته

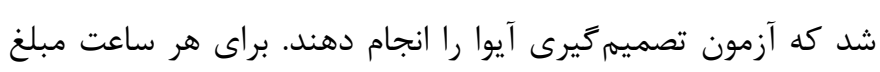

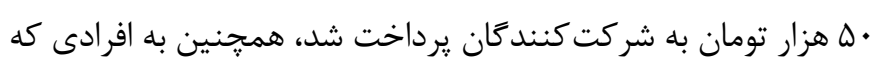

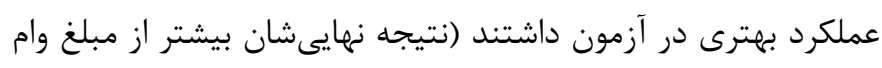

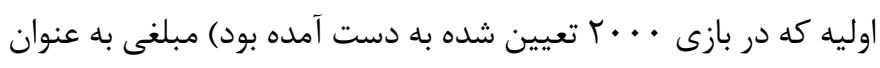

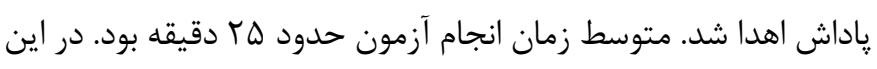

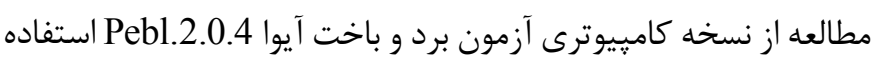

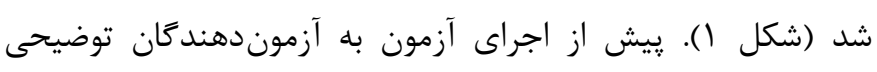


افراد مختلف تفاوت ارزش آنها يكسان نيست). يارامتر a ارزش كذارى

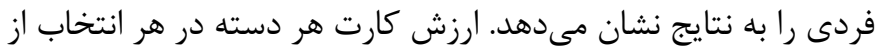

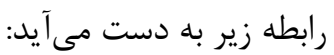

$S\left(A_{j}\right)=\sum_{i=1}^{n} u\left(x_{i j}\right) p_{i j}$

$u\left(x_{i j}\right)=\left\{\begin{array}{cl}x^{a} & \text { if } x \geq 0 \\ -|x|^{a} & \text { if } x<0\end{array}\right.$

كه در رابطه فوق تعريف عناصر، مشابه نظريه ارزش مورد انتظار است. در اين مدل تفاوتهاى فردى قابل مشاهده و مقايسه است. در اين برنامه براى به دست آمدن يارامتر a براى هر فرد تابع برازندىى به صورت تفاضل درصد جواب صحيح از صد در صد است كه هدف ما كمينه كردن اين تابع است. به طور مثال براى پارامترى كه به ازاء آن • V درصد جوابها با لهاب

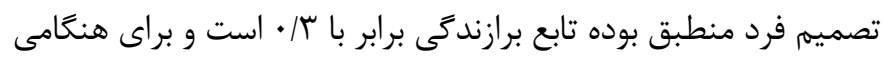

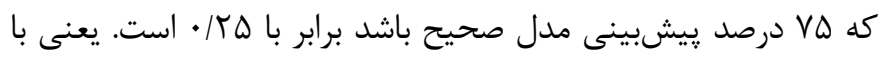

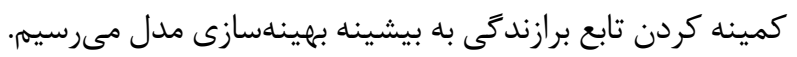

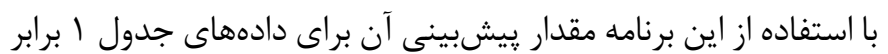

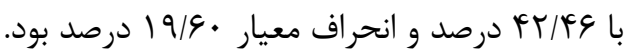
ج) نظريه جشم|نداز: نظريه جشم|نداز در سال 19 ارائه شده و يكى از مهمترين دلايل اهميت اين نظريه، شامل شدن اثر زيان گريزى است. اينكه بازنمايى ذهنى افراد از ضرر ير رنحتر از سود است. مدل ارتقا يافتهاى

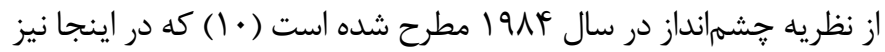

استفاده مىشود. تفاوت اين مدل بادو مدل قبلى به اين صورت است:

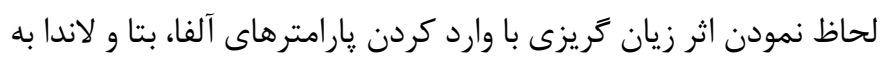

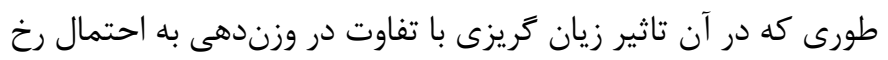
دادن سود و زيان مطالعه مىشود. يعنى بررسى آنكه آيا فرد زيان كريز

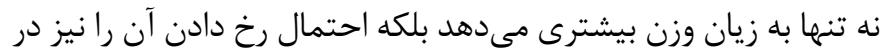
بازنمايى ذهنى خود ير رنتَتر مىبيند يا خير. بر اساس نظريه جشه|نداز ارزش انتخاب از هر دسته از روابط زير حاصل فئل

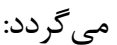
$S\left(A_{j}\right)=\sum_{i=1}^{n} v\left(x_{i j}\right) \pi\left(p_{i j}\right)$

$v\left(x_{i j}\right)=\left\{\begin{array}{ccc}x^{\alpha} & \text { if } x \geq 0 \quad \text { Gains } \\ -\lambda \cdot|x|^{\beta} & \text { if } x<0 & \text { Losses }\end{array}\right.$

$\left(p_{i j}\right)= \begin{cases}\frac{p^{\delta}}{\left(p^{\delta}+(1-p)^{\delta}\right)^{\frac{1}{\delta}}} & \text { Gains } \\ \frac{p^{\lambda}}{\left(p^{\lambda}+(1-p)^{\lambda}\right)^{\frac{1}{\lambda}}} & \text { Losses }\end{cases}$
طول آزمون ياد مى گيرند كه از كارتهاى با ٍِاداش كمتر بيشتر انتخاب كنند كه حاوى باخت يا تنبيه كمترى است.

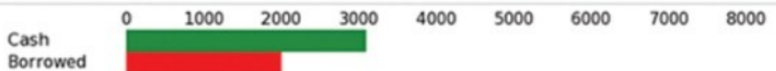

․ You have won $\$ 100$ !

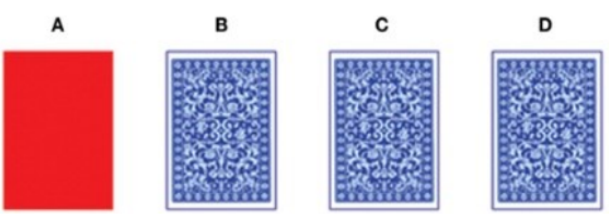

شكل ا. نمايى از آزمون كامبيوترى برد و باخت آيوا

روش مدل سازى: در ادامه به اعمال مدل هاى تصميم گيرى كه توضيح داده شد مى يردازيم. در برنامه تابع ارزش هر بار بر اساس هر يك المدي

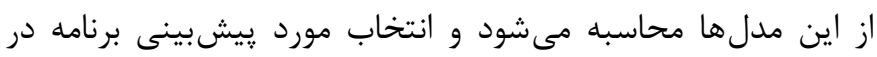

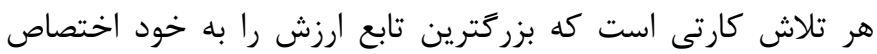

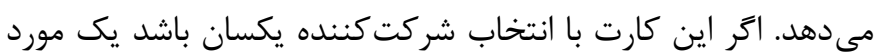

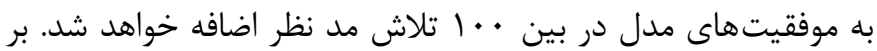
اين مبنا تابع ارزش مدلهاى مد نظر در برنامههاى جداكانه محاسبه كرديدند. در نهايت ميزان ييشبينى مدل ها با هم مقايسه شدند. الف) مدل ارزش انتظارى: بر اساس نظريه ارزش انتظارى، ارزش

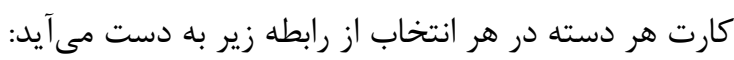

$S\left(A_{j}\right)=\sum_{i=1}^{n} x_{i j} p_{i j}$

كه در اين رابطه Aj انتخابهايى است كه فرد مىتواند انجام دهد و در

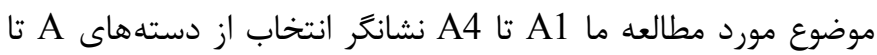

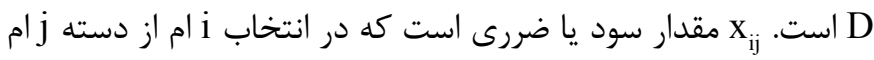
حاصل شده است. P احتمال حصول هر نتيجه است. S ارزش به دست آمده از مدل براى هر يك از انتخابها است. بر اساس اين نظريه در يك آند

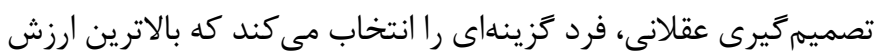
را داشته باشد. اين مدل فاقد يارامتر است يعنى وابسته به خصوصيات

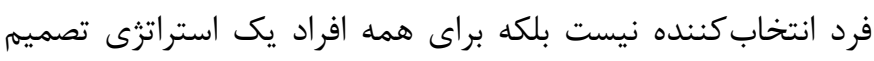

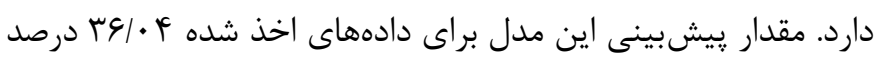

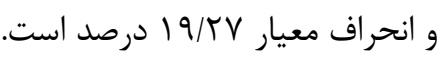
ب) مدل تسهيلات انتظارى: در اين نظريه يارامتر a وارد مىشود كه

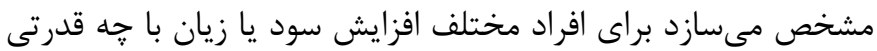

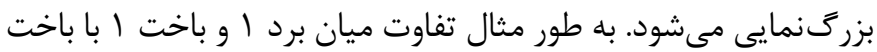

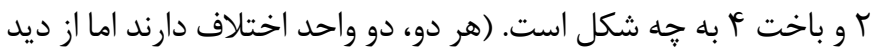


F مفهوم به عنوان ورودى مدل از آزمون آيوا استخراج شد و لايه ورودى را شكل داده است و با مقداركيرى در هر كوشش تابع ارزش را مى سازند. تعدادى از اين ورودى هاى اوليه به شرح زيرند (شكل سَ):

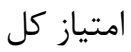
نتيجه مرحله قبلى مثبت نتيجه مر حله قبلى منفى بهترين خروجى اين دسته بدترين خروجى اين دسته تعداد كارت انتخابى از اين دسته فر كانس نتايج منفى فر كانس نتايج مثبت مجموع سود اين دسته مجموع ضرر از اين دسته مرحله فعلى مجنى

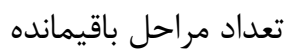

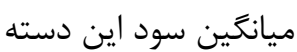
ميانگين ضرر اين دسته

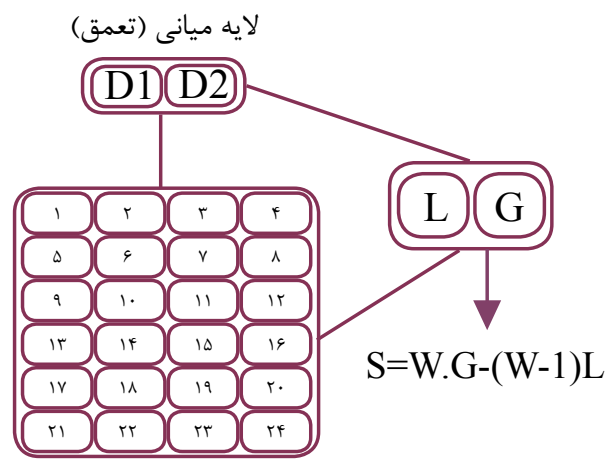

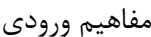

شكل r. مدل بِيوندكراى شناختى

وزنها به كَنهاى به دست مى آيند كه مدل بتواند بيشترين همخوانى را رال

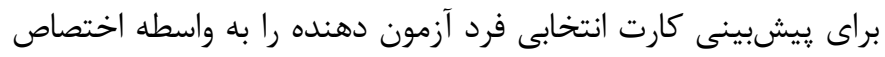

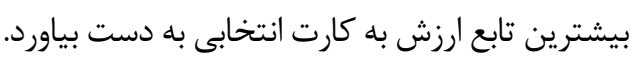

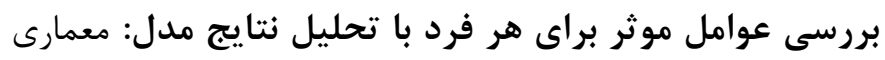

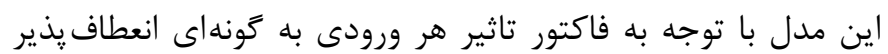
خود را با خصوصيات تصميم گيرى هر فرد تطبيق مى دهد. فاكتور تاثير براى مفهوم j ام عبارت است از نسبت تابع ارزش در زمانى كه به غير از مفهوم j ام، مقادير ساير مفاهيم صفر قرار داده شده باشد به إنه
در اين مدل نيز تفاوتهاى فردى قابل مشاهده و مقايسه است. مقدار

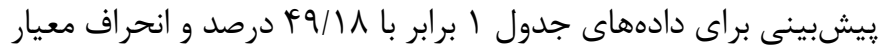

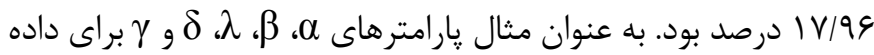

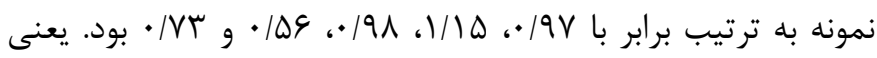

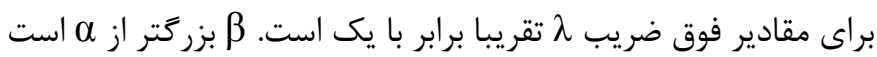

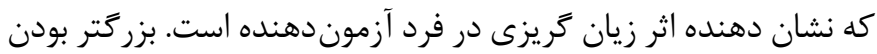

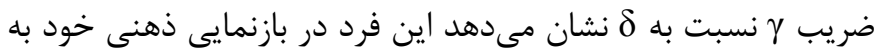
احتمال رخدادهاى زيانده وزن بيشترى مى دهد. د) مدل پييوندگراى شناختى: اين مدل شامل سه لايه كلى است، لايه ورودى، لايه تعمق و لايه خروجى (شكل r). لايه ورودى شامل

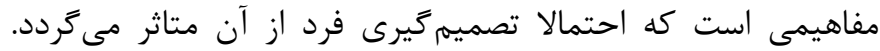
دستهاى از اين مفاهيم كه آن را مفاهيم اوليه مىنامند، شامل مفاهيمى

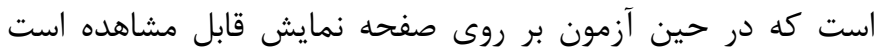
و دسته مفاهيم ثانويه كه شامل مفاهيمى است كه نياز به يه يردازش

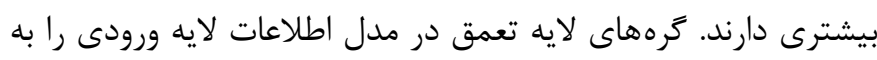

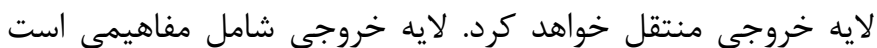
كه در ساخت تابع ارزش اهميت دارند، در ساخت مدل قيودى در ارتباطات بين گرهها حاكم است. به طور مثال، گرههاى يك تروه با

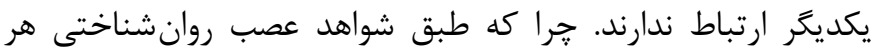

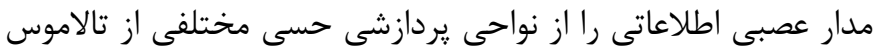

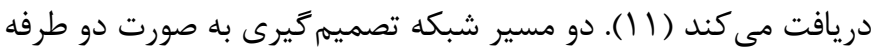

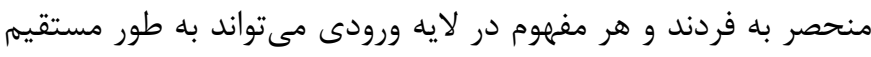

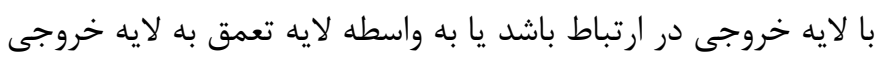

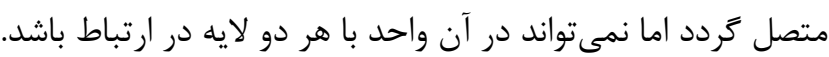
در اين مدل تابع ارزش به صورت زير تعريف مى مَردد:

$S\left(A_{j}\right)=\sum_{j=1}^{n} w G_{j}-(w-1) L_{j}$

مقادير پارامترهاى اين مدل همان وزن اتصالات مابين كرهها مىباشند كه براى هر شبكه محاسبه مى شوند.

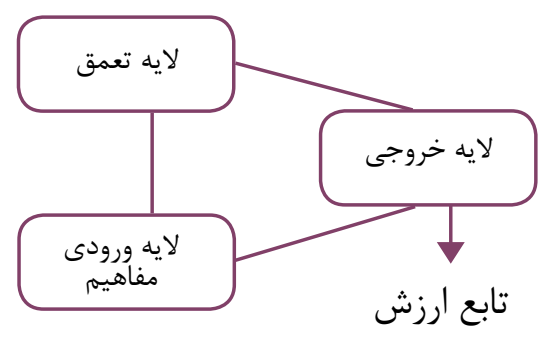

شكل r. شكل كلى مدل بيوندكراى شبكه تصميم 

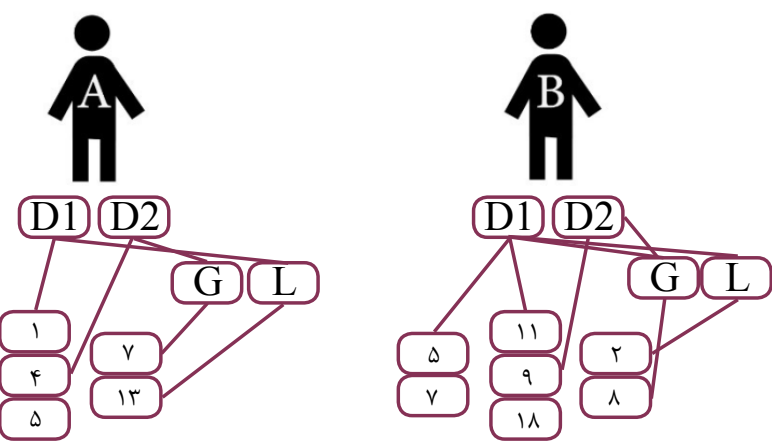

شكل F. شخصى سازى مدل براى هر فرد

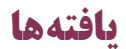

يس از اجراى مدلهاى كلاسيك تصميمَّيرى و مدل بيوندگراى

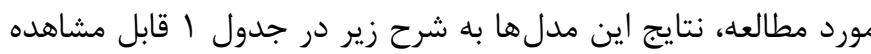

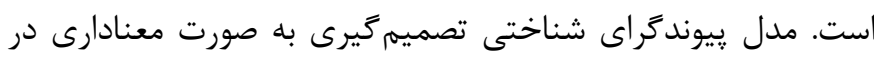
يِيشبينى انتخاب شركت كنندكان در آزمون برد و باخت آيوا عملكرد موفقترى از مدل هاى كلاسيك شناخته شده تصميم گيرى داشت.
تابع ارزش كل. يس از به دست آوردن فاكتور تاثير براى تمام مفاهيم

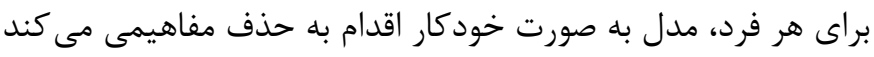

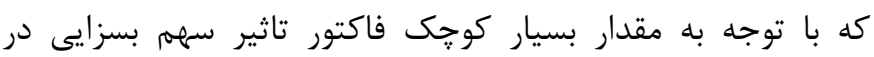

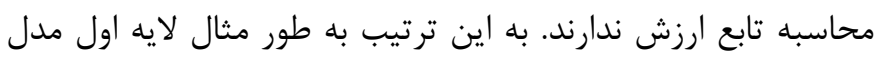

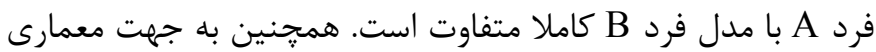
اتصالات، مدل بهينهترين حالت را براى هر فرد انتخاب مى كند به كونهاى كه مدل به بيشترين ميزان يِيشبينى انتخاب هاى فرد در آزمون دست يابد. اين امر يكى از مزاياى اين مدل مى باشد خرا كه

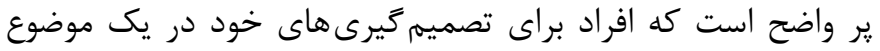
مشابه، به عوامل متفاوتى اهميت مى دهند (شكل أ).

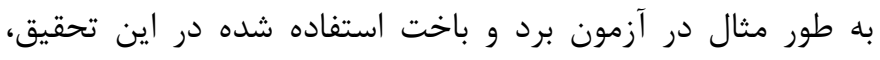

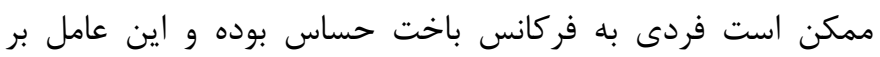
تصميم كيرى وى تاثير بسيارى داشته باشد و اين در حالى است كه

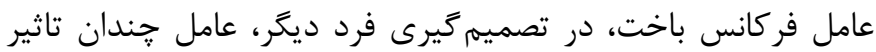
كذارى به حساب نمى آيد.

جدول ا. نتايج اعمال مدلها براى وه شركت كننده

\begin{tabular}{|c|c|c|c|c|c|c|}
\hline شناختى (درصد & جشم انداز & مطلوبيت انتظارى (درصد) & 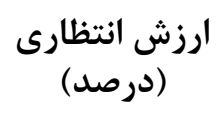 & جنس & سن & آزمودنى \\
\hline VT & Fr & r & $\Delta$. & مرد & $\Delta \Delta$ & 1 \\
\hline vr & Ve & Ve & $r$. & زن & $\Lambda \Delta$ & $r$ \\
\hline 91 & rF & rQ & TF & زن & $r$. & $r$ \\
\hline$v r$ & $v \Delta$ & $\mathrm{v \Lambda}$ & $r$. & زن & $V F$ & q \\
\hline VT & $q r$ & r & $\Delta q$ & زن & $\Delta \varphi$ & $\Delta$ \\
\hline 19 & (i) & rq & r & زن & $\Delta f$ & 4 \\
\hline$\Lambda r$ & r. & rv & $\wedge$ & زن & 10 & v \\
\hline vq & Mr & ra & $r_{1}$ & مرد & re & $\wedge$ \\
\hline $\mathrm{VA}$ & fr & ry & $r F$ & زن & $\Delta \Delta$ & 9 \\
\hline$\wedge$. & $\mu F$ & $r_{1}$ & rז & زن & $r v$ & 1. \\
\hline VT & rF & rT & ry & زن & $\Delta F$ & 11 \\
\hline$V^{F}$ & $\mu r$ & Tr & $r q$ & مرد & $r V$ & IT \\
\hline VI & rq & r & $r$. & مرد & TF & ז \\
\hline VT & rT & $r \Lambda$ & Ir & مرد & 99 & if \\
\hline 91 & c. & IV & $\Delta \varphi$ & زن & rq & 10 \\
\hline VF & $r \Lambda$ & $r$. & 10 & مرد & $\Delta r$ & 19 \\
\hline$V F$ & rF & rq & 11 & زن & $i \Delta$ & IV \\
\hline
\end{tabular}


ادامه جدول ا. نتايج اعمال مدل ها براى وه شركت كننده

\begin{tabular}{|c|c|c|c|c|c|c|}
\hline شنيوند (دراى & جشمى انداز & مطلوبيت انتظارى & 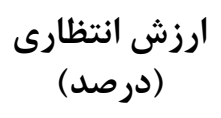 & جنس & سن & آزمودنى \\
\hline 49 & $r$. & qv & 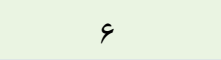 & زن & $r \Delta$ & 11 \\
\hline$V r$ & rT & r & If & مرد & $\Delta r$ & 19 \\
\hline v. & $r v$ & $r$. & is & زن & $r$ & $r$. \\
\hline$\Lambda V$ & GT & $r$. & 99 & زن & $\Delta r$ & rI \\
\hline $\mathrm{v}$. & rA & r & fr & زن & $r \Delta$ & Tr \\
\hline$v^{F}$ & $V r$ & $r$. & 99 & زن & $r V$ & r \\
\hline VI & rv & rq & $r$. & مرد & 99 & $T r$ \\
\hline 99 & זr & ro & eV & زن & rr & rQ \\
\hline GV & 99 & ro & GT & زن & $r F$ & rG \\
\hline$v$. & r & TA & $\Delta r$ & زن & $r_{4}$ & TV \\
\hline VI & VI & $9 \Delta$ & V. & زن & i) & rA \\
\hline v. & rv & rT & r. & زن & v. & rq \\
\hline$V^{\prime}$ & $r v$ & זr & $i \wedge$ & مرد & $r \Delta$ & $r$. \\
\hline$v^{F}$ & r & rT & TF & زن & $\Delta G$ & r \\
\hline VG & $\Delta \varphi$ & $r$. & Qr & مرد & $r_{F}$ & rT \\
\hline$q V$ & $\left.\right|_{1}$ & rT & $T F$ & مرد & ro & rז \\
\hline VA & pq & r. & $\psi_{1}$ & زن & r & $r F$ \\
\hline$v \Delta$ & ry & If & $\Delta r$ & مرد & $r q$ & ra \\
\hline $9 V$ & 11 & $v \Delta$ & ve & مرد & Tr & rq \\
\hline$V_{T}$ & $r$. & $r$. & Ir & مرد & $r \Lambda$ & $r v$ \\
\hline VT & rq & TA & 19 & مرد & $r F$ & r \\
\hline VI & rq & rq & rq & مرد & ro & rq \\
\hline vi & ro & IV & r & مرد & il & $r$. \\
\hline 49 & $r v$ & rq & $\Delta V$ & مرد & 90 & il \\
\hline$v$. & $\Delta 9$ & r & 99 & زن & r & Fr \\
\hline 99 & $\Delta r$ & $\Delta V$ & q & مرد & $r$. & Fr \\
\hline 99 & $4 q$ & is & $\Delta 9$ & مرد & $r V$ & fr \\
\hline$V^{r}$ & VV & 91 & $r$. & زن & 19 & $i \Delta$ \\
\hline$v^{\prime}$ & $v$. & VT & Tr & زن & rr & is \\
\hline 99 & Gr & Gr & FT & زن & r & qV \\
\hline VT & VT & VI & IV & زن & 19 & $\psi_{\Lambda}$ \\
\hline VT & 91 & $\Delta q$ & r & زن & rq & $4 q$ \\
\hline
\end{tabular}


ادامه جدول ا. نتايج اعمال مدل ها براى وه شركت كننده

\begin{tabular}{|c|c|c|c|c|c|c|}
\hline شنيوند (دراى & جشم انداز & مطلوبيت انتظارى & 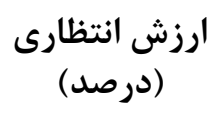 & جنس & سن & آزمودنى \\
\hline$v$. & VV & 91 & rr & زن & ґی & $\Delta$. \\
\hline VT & VI & 99 & r & زن & pV & DI \\
\hline$V r$ & $V F$ & Vr & IV & زن & pr & $\Delta r$ \\
\hline vr & VT & vq & r & زن & $\Delta \cdot$ & $\Delta r$ \\
\hline$v$. & IV & $q 4$ & Vr & زن & $\Delta V$ & $\Delta F$ \\
\hline VA & VA & VA & Tr & زن & 94 & $\Delta \Delta$ \\
\hline vq & ve & vq & $r V$ & زن & VT & $\Delta \varphi$ \\
\hline$V \Psi / \cdot T$ & $<q / / 1$ & KT/GS & $r \varepsilon / .4$ & & Fr/lF & ميانكَين \\
\hline$\Delta / \cdot \cdot$ & $1 V / 99$ & $19 / 9$. & $19 / T V$ & & $|V / r|$ & انحراف معيار \\
\hline
\end{tabular}

كز ينهای ممكن استفاده مى كند و سيس وزن ها محاسبه مى شوند. بِ إز آن به منظور مقايسه نتايج مدلها و يافتن مدلهايى كه بيشترين قابليت بيشبينى عملكرد آزموندهندكان در آزمون آيوا را دارند از شركت كنندكان سال خواسته شد در آزمون تصميم كيرى آيوا

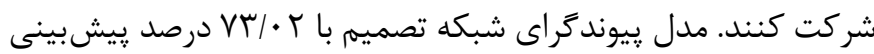
با انحراف معيار ه مطابق آنجه در جدول ا مشاهده مىشود در مقايسه

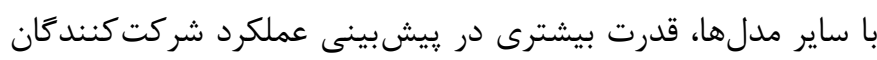

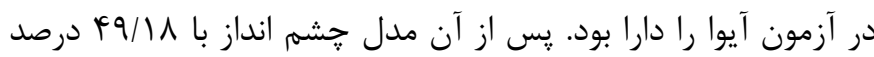

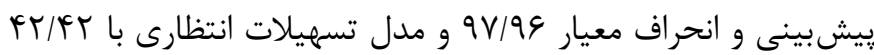
درصد يِشبينى و انحراف معيار • 19/9 در مراتب بعدى قرار مى گيرند. مشخصا مدل ارزش انتظارى با ميانگين \& •|ع درصد و انحراف معيار 19/TV درصد ضعيفترين مدل در زمينه يِيشبينى انتخابهاى

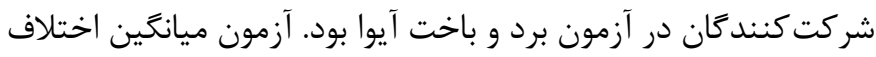

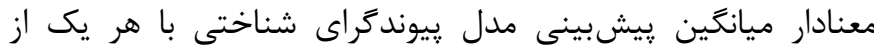

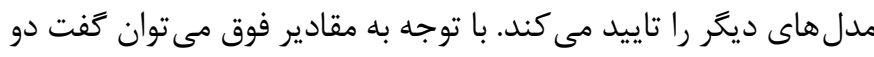

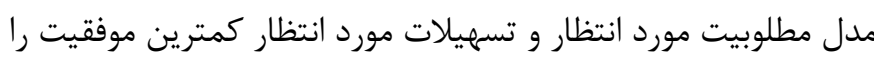

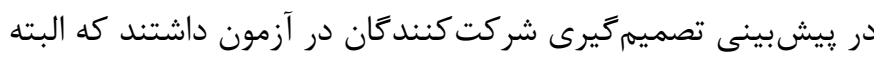
اين موضوع نتيجه مطالعات بيشين را تاييد مى كند (†).

\section{نتيجه كيرى} مىتوان كفت مدل هاى كلاسيك تصميم گيرى، روابطى رياضى هستند

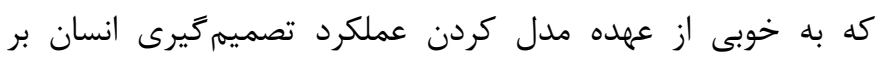

همانطور كه كفته شد تصميم گيرى يكى از مهمترين كاركردهاى شناختى انسان به شمار مىرود. در حوزه مدلسازى در زمينه تصميمَيرى مطالعات بسيارى انجام يذيرفته است و مدلهاى زيادى معرفى شدهاند (1). از مهمترين و معتبرترين مدلهاى كلاسيك اين حوزه مىتوان مدلهاى ارزش انتظارى، تسهيلات انتظارى و نظريه

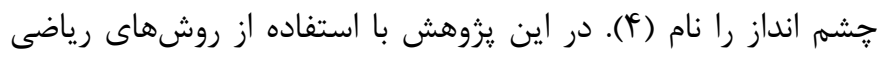

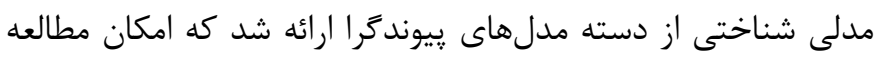

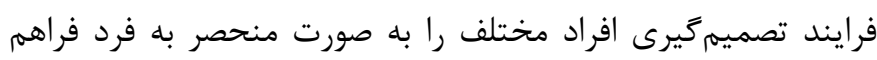

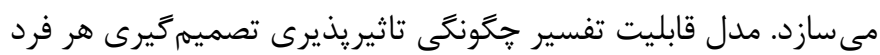
از ساير فرآيندهاى شناختى مانند: حافظه، ادراك و ... را با توجه به فيه ميزان تاثير ورودىهاى اوليه يا ثانويه براى ما ممكن مىسازد. به اين منظور اطلاعات موجود در محيط آزمون و تجربيات ممكن براى افراد كه مى توانند مبناى تصميمَيرى باشند به شكل ورودى هاى شناختى در دو دسته ورودى هاى اوليه و ثانويه وارد شبكه مىشوند. ورودى هاى اوليه ورودى هايى هستند كه نياز به تفسير در سطح حافظه كارى ندارند

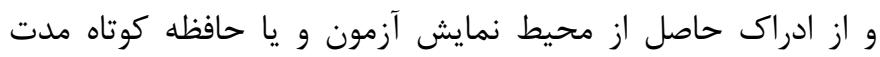

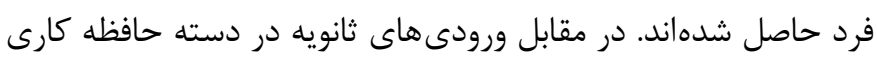
قرار مى گيرند و نيازمند يردازش هستند. اين دو دسته ورودى مفاهيم

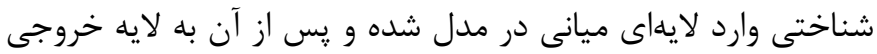

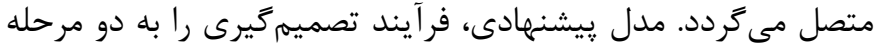
تقسيم مى كند. مرحله اول تخمين خروجى تصميم بر مبناى شبكه

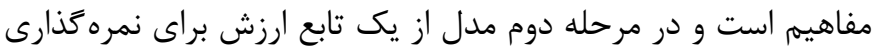


درك كنيم. اين شيوه مدلسازى قابل اجرا بر روى آزمونهاى مختلف تصميم گيرى است و همجنين توسط اين مدل مى توان تصميمى گيرى فرد در شرايط مختلف را مدل كرد. در مطالعات بعدى مىتوان از اين مدل جهت مطالعه مفاهيم موثر بر تصميمگيرى افراد با اختلالات مختلف و مونى بررسى جگَّنكى تصميم گيرى اين افراد استفاده كرد.

\section{تشكر و قدرفاذى}

بدينوسيله از زحمات كليه شركت كنند اين مطالعه يارى رساندند، تشكر و قدردانى به عمل مى آيد.

\section{References}

1 .Boyle GJ, Matthews G, Saklofske DH, editors. Handbook of personality theory and assessment: Personality measurement and assessment (Vol 2). 1st ed. California:SAGE Publications;2008. 2. Bargh JA, Ferguson MJ. Beyond behaviorism: On the automaticity of higher mental processes. Psychological Bulletin. 2000;126(6):925-945.

3. Shahsavarani AM, Azad Marz Abadi E. The bases, principles, and methods of decision-Making: A review of literature. International Journal of Medical Reviews. 2015;2(1):214-225. 4. Tversky A, Kahneman D. Advances in prospect theory: $\mathrm{Cu}-$ mulative representation of uncertainty. Journal of Risk and Uncertainty. 1992;5(4):297-323.

5. Beitz KM, Salthouse TA, Davis HP. Performance on the Iowa Gambling Task: From 5 to 89 years of age. Journal of Experimental Psychology: General. 2014;143(4):1677-1689.

6. Wagar BM, Thagard P. Spiking Phineas Gage: A neurocomputational theory of cognitive-affective integration in decision making. Psychological Review. 2004;111(1):67-79.

7. Levine DS, Mills B, Estrada S. Modeling emotional influences on human decision making under risk. In Proceedings.

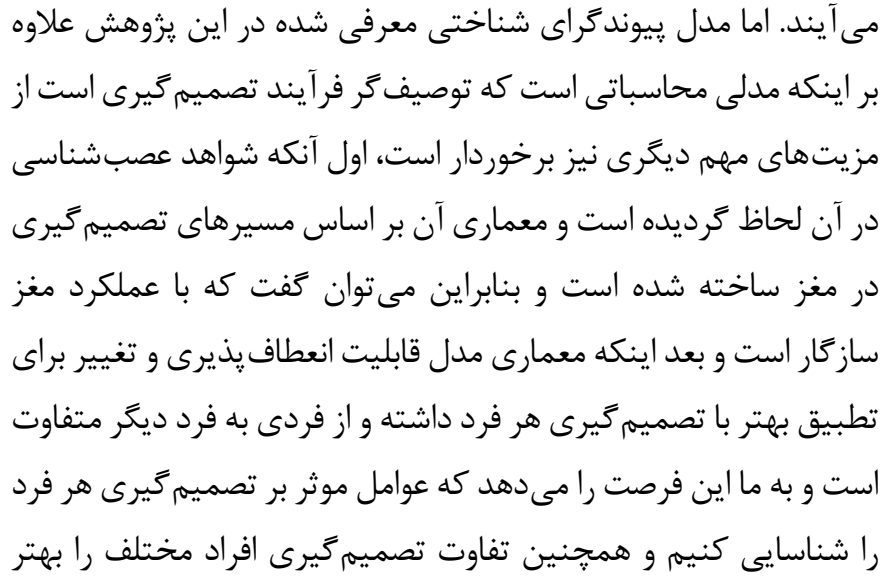

2005 IEEE International Joint Conference on Neural Networks, 2005. 2005 Jul 31 (Vol. 3, pp. 1657-1662). IEEE.

8. Schoemaker PJ. The expected utility model: Its variants, purposes, evidence and limitations. Journal of Economic Literature. $1982 ; 20(2): 529-563$.

9. Allais M. Allais paradox. In: Durlauf SN, Blume LE, editors. The new Palgrave dictionary of economics: Volume 1-8 [Internet]. London:Palgrave Macmillan UK;2008 [cited 2018 Dec 26]. pp. 119-22.

10. Kahneman D, Tversky A. The Simulation Heuristic. In Kahneman D, Slovic P, Tversky A, editors. Judgment under uncertainty: Heuristics and biases. Cambridge:Cambridge University Press;1982. pp. 201-208.

11. Romanski LM, LeDoux JE. Equipotentiality of thalamo-amygdala and thalamo-cortico-amygdala circuits in auditory fear conditioning. Journal of Neuroscience. 1992;12(11):4501-4509.

12. Bechara A, Damasio AR, Damasio H, Anderson SW. Insensitivity to future consequences following damage to human prefrontal cortex. Cognition. 1994;50(1):7-15. 